\title{
Chemical Fixation of Carbon Dioxide to Propylene Carbonate in Ionic Liquids
}

\author{
Yu-jin Kim and Minserk Cheong \\ Department of Chemistry and Research Instinte for Basic Sciences, Kyung Hee Linversity, Seoul 130-701. Korea \\ Received April 12.2002
}

Keywords : Carbon dioxide, Propylene carbonate, Ionic liquid.

The efficient transformation of harmful wastes such as $\mathrm{CO}_{2}$ into useful chemicals is an important contribution to the preservation of the carth. Chemical lixation of $\mathrm{CO}_{2}$ onto organic compounds is interesting because of a synthetic merit; one carbon atom and two oxygen can be incorporated in one step with a high atom elficiency. The conversion of $\mathrm{CO}_{2}$ into carbonates has been carricd out in conventional organic solvents using catalysts such as dialkyltin methoxide, ${ }^{1}$ organoantimony halide, ${ }^{2}$ alkali metal salts, ${ }^{3} \mathrm{Mg}-\mathrm{Nl}$ mixed metal oxide and $\mathrm{Cr}(\mathrm{lll})$ salen complex. ${ }^{5}$ In particular, the addition reaction of $\mathrm{CO}_{2}$ to cpoxide is a powerlul candidate for $\mathrm{CO}_{2}$ lixation to produce live-membered cyclic carbonate which can be used as valuable raw materials for engineering plastics and highly polar solvents. " However, these reactions using metallic catalysts have disadvantages, such as poor solubility of the catalyst, ${ }^{3}$ difliculties in catalyst recycling, ${ }^{2}$ air sensitivity, the need for co-solvent, or the requirement for high temperatures.

Many organic solvents evaporate into the atmosphere with detrimental eflects on the environment and human health. But room-lemperature ionic liquids, with low viscosity and no measurable vapour pressure, ${ }^{7}$ can be used as environmentally benign media for a range of industrially important chemical processes, ${ }^{8-12}$ despite uncertainties about thermal stability and sensitivity to oxygen and water. Ilere, we found that using ionic liquids as solvents as well as catalysts can improve the reaction rate significantly at low temperalutes (Scheme I).

Numerous low-melting ionic salts are known, including alkylphosphonium, $N$-alkylpyridinium, alkylammonium, and $N N^{\prime}$-alkylimidazolium cations with various anions. ${ }^{13}$ We chose to use the 1-alkyl-3-methylimidazolium cation because: (i) their synthesis is facile, ${ }^{14}$ and (ii) it is neither oxygen nor water sensitive (but is hygroscopic). With iodide as the counteranion, whose role has been extensively studied in our previous studies. ${ }^{15}$ they can act as solvents as well as catalysts.

$\Lambda$ typical experimental procedure for the carboxylation of

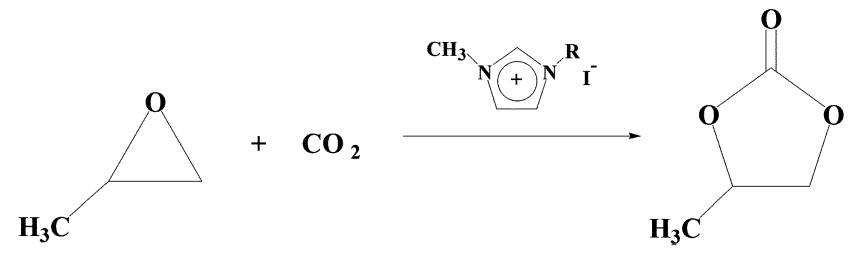

Scheme 1 epoxide with carbon dioxide is as follows. Propylene oxide $(0.4 \mathrm{~mol})$ was added to $\mathrm{I}$-alkyl-3-methylimidazolium iodide $(10 \mathrm{~g})$ in a $125 \mathrm{~mL}$ Parr reactor at room temperature, and $\mathrm{CO}_{2}(30 \mathrm{~atm})$ was introduced into the reactor and then the mixture was heated up to the desired temperature. The reaction was started by stirring the mixture and continued for I h. After the reaction, the pressure was released and the product was quenched with ice-water and analyzed by NMR and GC-MS spectroscopy. The yiclds of carbonates were determined by GC using 1-methyl-2-pyrtolidinone as an internal standard. Under reaction conditions we studied, carbonate was the main product with trace amounts of a few byproducts. ${ }^{16}$

The results in Table 1 show that our concept of using ionic liquid both as a solvent as well as a catalyst works pretty well. Even though DMF was used in the same way in the production of styrene carbonate under supercritical condition. the reaction conditions were much harsher $\left(150^{\circ} \mathrm{C}\right.$ for 15 h)..$^{17}$ Under our reaction conditions, only $3.5 \%$ of carbonate was obtained using DMF as a solvent even with added catalyst (run 10). Depending on the alkyl groups attached to the imidazole ring, the solubilities and melting points of the ionic liquid change signilicantly. ${ }^{18}$ When symmetrically substituted 1,3-dimethylimidazolium iodide $\left(\left[C_{1}, \mathrm{mim} \mid[[])\right.\right.$.

Table 1. Carboxylation of propylene oxide with carbon dioxide in diflèrent reaction system

\begin{tabular}{|c|c|c|c|c|c|}
\hline Run & Catalyst & Solvent & Temp. & $\underset{h}{\operatorname{lime}}$ & $\begin{array}{c}\text { Yicld of } \\
\text { carhonato } \\
(\%)^{\text {id }}\end{array}$ \\
\hline 1 & None & {$\left[C_{1}\right.$ mim ||$\left.I\right]$} & 50 & I & 7.9 \\
\hline 2 & None & {$[$ C.mim ||$I]$} & 60 & I & 11 \\
\hline 3 & None & {$[C, m i m|| I]$} & 70 & I & 85 \\
\hline 4 & None & {$[$ C.mim ||$I]$} & 80 & I & 78 \\
\hline 5 & None & {$\left[C_{4}\right.$ mim $\mid[\mid]$} & 30 & I & 5.8 \\
\hline 6 & None & {$\left[C_{4}^{\prime}\right.$ mim ||$\left.I\right]$} & 40 & I & 26 \\
\hline 7 & None & {$\left[C_{+}\right.$mim $\mid[I]$} & 50 & I & 87 \\
\hline 8 & None & {$[C+m i m \mid[I]$} & 60 & I & 86 \\
\hline$y^{/ /}$ & $/ \mathrm{nl}_{2}$ & {$[C+m i m \mid[I]$} & 40 & I & 100 \\
\hline $10 c^{c}$ & $/ \mathrm{nl}_{2}$ & DMF: & 40 & I & 3.5 \\
\hline $11^{t}$ & Cr(III) Salen & DMAPCCII & 75 & 1.5 & 100 \\
\hline $12^{*}$ & $\begin{array}{l}M g-\Lambda 1 \text { mixed } \\
\text { oxide }\end{array}$ & DMF & 120 & 24 & 88 \\
\hline
\end{tabular}

"The yiclds are determined by $\mathrm{CC}$ analysis based on the area ratio of $1-$ methyl-2-pyrrolidinone as an intemal references. " $\mathrm{Znl} \mathrm{l}_{2}(0.4 \mathrm{mmol})$ wess

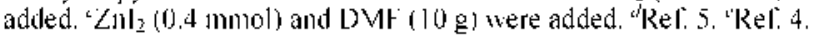


which is solid at room temperature, was used as a solvent. it does not become homogeneous until the reaction temperature goes above $70{ }^{\circ} \mathrm{C}$ (runs $1-1$ ). but only acts as a solid catalyst dissolved in neat propylene oxide at low temperatures. In case of asymmetrically substituted 1-butyl-3metlyylimidazolium iodide $\left(\left[\mathrm{C}_{-1}\right.\right.$ mim $\left.][1]\right)$. which is liquid at room temperature, it can act as a solvent even at $40^{\circ} \mathrm{C}$. At ligher temperatures, decrease in solubility of $\mathrm{CO}_{2}$ in ionic liquid might play a role. since the reactant concentration is quite high (almost $40 \mathrm{M}$ ) under our reaction conditions. Whicherer ionic liquid was used as a solvent. the yields are quite high and reaction conditions are extremely mild considering that no metallic catalysts have been used. Previous reports on synthesis of cyclic carbonates from $\mathrm{CO}_{2}$ and epoxides suggest the parallel requirement of both Lewis-base-activation of the $\mathrm{CO}_{2}$ and Lewis-acid-activation of the epoxide. ${ }^{4,5}$ Lewis basic activation of the $\mathrm{CO}_{2}$ by iodide ion has been well understood. Therefore, adding simple Lewis acidic catalysts such as Znd can improve the reaction rate significantly (nun 9). Without any sophisticated ligand, this catalyst system gives high tumover frequencies of almost $1000 \mathrm{~h}^{-1}$.

Remaining reactants and products are both easily removed from the reaction mixture via distillation. completely eliminating the use of organic solvent.

In summary, this catalyst system is highly efficient toward the coupling of carbon dioxide with epoxides at mild temperatures. Also it represents an air stable, easily synthesized catalyst system for $\mathrm{CO}_{2}$ fixation which requires no organic solvent.

Acknowledgment. This work was supported by Korea Research Foundation Grant (KRF-2000-0+1-D00158).

\section{References and Notes}

1. Choi J-C.: Sakakura. I.: Saho. J. J. Am. Chem Soc 1999. I2I. 3793.

2. Matsuda. H.: Ninagawa. A.: Nomura. R.: I luschida. T, Chem. Lutt. $1979,573$.

3. Kihara, N.; Hara. N.: T.1do. T. J. Org. (hem 1993, 58,6198

4. Yamaguchi, K.: Fbitani, K.: Yoshida. T.: Yoshida. II.: Kancda, K. J. Am. Chom. Soc. 1999. 121.4526.

5. Paddock. R. L.: Nguyen. S. I. $J$. Am. Chmm. Soc. 2001. 123. $11+98$.

6. (a) Darensbourg. D. J.: Holtcamp. M. W. C'oord (hem Rev 1996. 15j, 155. (b) Peppel, W. J. Ihd Thg. (hem. 1958, 50, 767. (c) Ratzenhoter. M.: Kisch. I I. ingew ('hem. Int. Ed Engl 1980. 19. 317. (d) Rakicki. G.: Kuran. W.: Marciniak. B. P'. Momat. (Chem. 1984. 115. 205, (e) Yano. T.: Matsui. H.: Koike. T.: Ishiçuro. H: Fujihara. H.: Yoshihara. M.: Maeshima. T. Chem. Common. 1997. 1129.

7. Seddon, K. R.J. (hem. Tech Biotecinol 1997, 68. 351

8. Chaurin, Y.: Olivicr-Bourbigou. II. Chemtech 1995. 25. 26.

9. Adums. C. I.: Earle. M. I.: Roberts. G.: Seddon. K. R. Chem. Commm. 1998. 2097.

10. Earle. M. J.: McCormac. P. B.: Seddon. K. R. Chem. Commm. 1998,2245

11. Farle, M. J.: MeCormac, P. B.: Seddon, K. R. Gren Chem 1999. I. 2.3

12. Ellis. B.: Keim. W.: Wasserscheid. P. Chem. Commm. 1999. 337.

13. Welton. T. Chem. Rev 1999. 99. 2071.

14. The 1-alkyl-3-methylimidazolium iodide is readily synthesized from 1-alkylimidazole and iodothethane. (see reference 18).

15. (a) Cheong. M.: Kim. S.-C.: Park, J. B. Yen' J. Chem 1997, 21, 1143. (b) Chu. G. II.: Park. J. B.: Cheong. M. Inorg. Chim. tcta 2000. 307.131 .

16. The total amount of these minor products is less than $1^{\circ}$ o from the GC analyses.

17. Kawanami, II.: Ikushima, Y. (hem. ('ommmn. 2000. 2089

18. Iluddleston, I. G.. Visser. A. F.. Reichert, W. M.: Willauer. H. D.: Broker, G. A. Rogers. R. D. Green (Wem 2001, 3. 156. 